\title{
MicroRNA-520a suppresses the proliferation and mitosis of HaCaT cells by inactivating protein kinase $B$
}

\author{
RUI WANG, ZIGANG ZHAO, LIQIANG ZHENG, XIAOJING XING, WEI BA, JUNFEN ZHANG, \\ MIN HUANG, WENWEI ZHU, BING LIU, XIANFU MENG, JIA BAI, CHENGXIN LI and HENGJIN LI \\ Department of Dermatology, Chinese People's Liberation Army General Hospital, \\ Medical College of The Chinese People's Liberation Army, Beijing 100853, P.R. China
}

Received February 15, 2017; Accepted August 21, 2017

DOI: $10.3892 /$ etm.2017.5323

\begin{abstract}
Psoriasis is a chronic inflammatory disease of the skin for which an effective treatment strategy remains to be developed. Characteristics of psoriasis include an altered differentiation of keratinocytes and hyperplasia of the skin. The present study aimed to investigate the role served by miR-520a in psoriasis. The results demonstrated that miR-520a inhibited the proliferation of $\mathrm{HaCaT}$ cells. miR-520a directly regulated the mRNA and protein expression of its target gene, protein kinase B (AKT). The siRNA silencing of AKT expression in these cells was also evaluated. miRNA-520a repressed the proliferation and mitotic entry of $\mathrm{HaCaT}$ cells, and promoted cell apoptosis. AKT silencing suppressed the proliferation of $\mathrm{HaCaT}$ cells. These results suggest that miRNA-520a regulates the survival of $\mathrm{HaCaT}$ cells by inhibiting AKT expression. miRNA-520a and AKT may therefore be novel targets for the treatment of patients with psoriasis.
\end{abstract}

\section{Introduction}

Psoriasis is a chronic inflammatory disease of the skin that affects $0.1-3 \%$ of the population worldwide $(1,2)$. Characteristics of the disease include altered differentiation of keratinocytes and hyperplasia of the skin (1). Common treatments for psoriasis include herbal therapy and systemic, topical, combination and phototherapy treatments, which inhibit excessive keratinocyte proliferation (3). Although there are a variety of therapies available to treat psoriasis, no cure has been developed and the relapsing-remitting nature of psoriasis continues to adversely affect patient quality of life $(4,5)$. The pathophysiology of psoriasis is not well understood. Genetic

Correspondence to: Professor Hengjin Li, Department of Dermatology, Chinese People's Liberation Army General Hospital, Medical College of The Chinese People's Liberation Army, 28 Fu Xing Road, Beijing 100853, P.R. China

E-mail: lhengjin@163.com

Key words: microRNA, psoriasis, proliferation, mitosis, keratinocytes and auto-immunological mechanisms are suspected, but no single unified theory exists to explain the nature of the disease.

MicroRNAs (miRNAs) are a group of small, non-coding RNAs that are 22-25 nucleotides long and post-transcriptionally regulate gene expression (6). miRNAs control gene expression by pairing with incompletely matching target sites of the 3'-untranslated regions (3'UTRs) of mRNAs, causing translational repression and/or mRNA destabilization, thereby downregulating the expression of the targeted gene. There are an increasing number of studies on the vital function of miRNAs in regulating expression at the post-transcriptional level. There has been a focus on the role of miRNAs in numerous biological progressions, including inflammatory disorders (7), and a variety of miRNAs are regarded as a novel category of inflammatory mediators in human diseases (8-11).

The transcription factor E2F transcription factor 2 is downregulated by miR-520a, which subsequently suppresses the cell cycle progression and proliferation of hepatoma cells (12). Glabridin (GLA) is a novel antitumor medicine that suppresses inflammation, proliferation and oxidization in cancer cells. miR-520a promotes the antitumor role of GLA by inhibiting the nuclear factor $(\mathrm{NF})-\kappa \mathrm{B}$ signalling pathway and GLA upregulates the expression of miR-520a. miR-520a combines with the 3'UTR of the NF- $\mathrm{B}$ p65 subunit and inhibits its expression (13). Wang et al (14) demonstrated that miR-520a may be a key regulator of endoplasmic reticulum (ER) stress and the proliferation of Raji cells (human B lymphoma cell line), and may be associated with the PRKR-like ER kinase/eukaryotic translation initiation factor 2 subunit $\alpha$ and protein kinase $B$ (AKT1)/NF- $\kappa$ B signalling pathways. miR-520a specifically binds to the 3'UTR of AKT1 mRNA, and is a crucial mediator for inhibiting proliferation of Raji cells. Therefore, the use of miR-520a may be a potential therapeutic strategy for treating Burkitt's lymphoma.

In vitro studies on the differentiation of keratinocytes are hindered due to the inherent properties of keratinocytes and the limitations of the stringent requirements for their culture (15). Primary keratinocytes have a finite life span, while transformed cell lines exhibit many phenotypic features not found in normal cells (15). HaCaT cells are spontaneously immortalized human keratinocytes, which have been widely used based on their near normal phenotype and easy 
propagation (15). They have been used previously as a model for epidermal keratinocytes in the study of multiple diseases, including psoriasis (16). The present study demonstrated that miR-520a suppresses HaCaT cell proliferation.

Treatment strategies for psoriasis remain elusive. The phosphatidylinositol 3-kinase (PI3K)/AKT pathway has recently been identified to be associated with psoriasis (17). AKT was predicted as the target gene of miR-520a in the present study and AKT may serve a crucial role in the proliferation of $\mathrm{HaCaT}$ cells. Therefore, the present study highlights a potential method to suppress the proliferation of $\mathrm{HaCaT}$ cells with miR-520a through the AKT pathway.

\section{Materials and methods}

Cell line. The HaCaT cell line was purchased from NTCC (cat. no. 340383; Biovector Science Lab, Inc., Beijing, China). $\mathrm{HaCaT}$ cells were used for an in vitro model of psoriasis and cultured in Dulbecco's modified Eagle's medium (Invitrogen; Thermo Fisher Scientific, Inc., Waltham, MA, USA) supplemented with $10 \%$ fetal bovine serum (Invitrogen; Thermo Fisher Scientific, Inc.), penicillin and streptomycin. The cells were cultured at $37^{\circ} \mathrm{C}$ with $5 \% \mathrm{CO}_{2}$.

Reagents. Lipofectamine 2000, the mirVana miRNA Isolation kit and the TaqMan miRNA assay kit were obtained from Thermo Fisher Scientific, Inc. The Luc-Pair ${ }^{\mathrm{TM}} \mathrm{miR}$ Luciferase Assay kit (cat. no. S900042) for detecting the 3'-UTR luciferase reporter gene of AKT was obtained from SwitchGear Genomics (Menlo Park, CA, USA). The assay kits for cell proliferation (BrdU Assay kits) were purchased from Promega Corporation (Madison, WI, USA). The control small interfering (si)RNA (cat. no. sc-37077) and anti-AKT siRNA (cat no. sc-38910) were both obtained from Santa Cruz Biotechnology Inc. (Dallas, TX, USA). The mimics of human miR-520a were purchased from Applied Biosystems (cat. no. KIT 001168; Thermo Fisher Scientific, Inc.), and the scramble miRNA as negative control (cat. no. SI03650325) and inhibitors (cat. no. GS574467) were purchased from Qiagen China Co., Ltd. (Shanghai, China). The miR-520a mimics and inhibitors were transfected based on the manufacturer's instructions for Lipofectamine 2000.

Reverse transcription-quantitative polymerase chain reaction (RT-qPCR) analysis. Total RNA was extracted from cultured HaCaT cells with TRIzol ${ }^{\circledR}$ (Invitrogen; Thermo Fisher Scientific, Inc.) according to the manufacturer's instructions, and RT was then performed using the Access Quick RT-PCR system (Promega Corporation, Madison, WI, USA) at $44^{\circ} \mathrm{C}$ for $1 \mathrm{~h}$ followed by $92^{\circ} \mathrm{C}$ for $10 \mathrm{~min}$. RT-qPCR analysis was conducted using the ABI 7,500 Real-Time PCR system (Applied Biosystems; Thermo Fisher Scientific, Inc.). Thermocycling conditions were as follows: $2 \mathrm{~min}$ at $95^{\circ} \mathrm{C}$ followed by 30 to 32 cycles of $30 \mathrm{sec}$ at $94^{\circ} \mathrm{C}, 30 \mathrm{sec}$ at $58^{\circ} \mathrm{C}$ and $30 \mathrm{sec}$ at $72^{\circ} \mathrm{C}$, with a final extension for $10 \mathrm{~min}$ at $72^{\circ} \mathrm{C}$. GAPDH was used as an internal control and results were quantified using the $2^{-\Delta \Delta \mathrm{Cq}}$ method (18). GAPDH was used as the control. The primer sequences were as follows: AKT forward, 5'-TGGACTACC TGCACTCGGAGAA-3' and reverse, 5'-GTGCCGCAAAAG GTCTTCATGG-3'; GAPDH forward, 5'-GTCTCCTCTGAC
TTCAACAGCG-3' and reverse, 5'-ACCACCCTGTTGCTG TAGCCAA-3'.

Western blot analysis. Total protein was extracted from lysed cells with radioimmunoprecipitation assay buffer (Cell Signaling Technology, Inc., Danvers, MA, USA) and the protein concentrations were measured using a BCA Protein Assay (Pierce; Thermo Fisher Scientific, Inc.). Equivalent amounts of protein $(20 \mu \mathrm{g} /$ well $)$ were separated by $10 \%$ SDS-PAGE. Following electrophoretic transfer of the proteins to a nitrocellulose membrane, the membrane was blocked for $1 \mathrm{~h}$ at $22^{\circ} \mathrm{C}$ with $5 \%$ dried milk. The membrane was incubated with primary antibodies (dilution 1:2,000) overnight at $4^{\circ} \mathrm{C}$ followed by secondary antibodies in $5 \%$ dried milk for $1 \mathrm{~h}$ at $22^{\circ} \mathrm{C}$. Primary antibodies were as follows: $\beta$-actin (sc-58673) and anti-AKT (sc-24500) (both from Santa Cruz Biotechnology, Inc.). The secondary antibodies, rabbit anti-mouse IgG (Light Chain Specific; D3V2A) and $\mathrm{mAb}$ (no. 58802; both 1:5,000) were obtained from Cell Signaling Technology, Inc. Protein bands were detected using an enhanced chemiluminescence detection kit (GE Healthcare Life Sciences, Little Chalfont, UK).

Luciferase reporter assays. miRNA-target prediction software DIANA microT (http://diana.imis.athena-innovation.gr/ DianaTools/index.php? $r=$ microtv4/index; version 4.0) was used to predict the 3'UTR targets of miR-520a, 5'-AAUAAA AGUGACUUGAGCACUUA-3', which were then amplified by PCR with the Geneamp XL PCR kit (Thermo Fisher Scientific, Inc.) using DNA extracted from $\mathrm{HaCaT}$ cells and subsequently cloned into pmirGLO plasmids. The thermocycling conditions of PCR were as follows: $5 \mathrm{~min}$ at $95^{\circ} \mathrm{C}$ followed by 25 cycles of $30 \mathrm{sec}$ at $94^{\circ} \mathrm{C}, 30 \mathrm{sec}$ at $55^{\circ} \mathrm{C}$ and $1 \mathrm{~min}$ at $72^{\circ} \mathrm{C}$, with a final extension for $10 \mathrm{~min}$ at $72^{\circ} \mathrm{C}$. The following primers were used: forward, 5'-CUCAGGCUGUGACCCUCCAGAGGG AAGUACUUUCUGUUGUCUG-3' and reverse, 5'-GAG UUUGGCUUUGUCAGGUUUCCCUUCGUGAAAGAAA AGAGAG-3' (Invitrogen; Thermo Fisher Scientific, Inc.). The pmirGLO-3'-UTR of AKT construct plasmids and the control were transfected into cells using Lipofectamine 2000 according to the manufacturer's instructions. The activity of luciferase was then analyzed with a dual-luciferase reporter system (cat. no. E1910, Dual-luciferase assay system; Promega Corporation) following transfection for $48 \mathrm{~h}$. Signals from reporter genes were normalized to Renilla luciferase.

Bromodoexyuridine (BrdU) assays and mitotic index analysis. Cells were synchronized for $16 \mathrm{~h}$ using the block method with double thymidine (19). Cells were then released and collected, or fixed for assays, $1 \mathrm{ml}$ of Carnoy's fixative (3 parts methanol, 1 part glacial acetic acid) at $-20^{\circ} \mathrm{C}$ for $20 \mathrm{~min}$. DNA synthesis or mitotic entry analysis was performed using the BrdU-fluorescein isothiocyanate (FITC) labeling method (20). Cells were counted using an immunofluorescence microscope and then the number of BrdU-FITC-positive cells was quantified. The fluorescence excitation and emission wavelengths were set to 488 and $525 \mathrm{~nm}$, respectively.

Mitotic events were determined using Hoechst 33258 DNA staining for $5 \mathrm{~min}$ at $37^{\circ} \mathrm{C}$ and time-lapse video microscopy. Following synchronization, real-time images of the cells were 


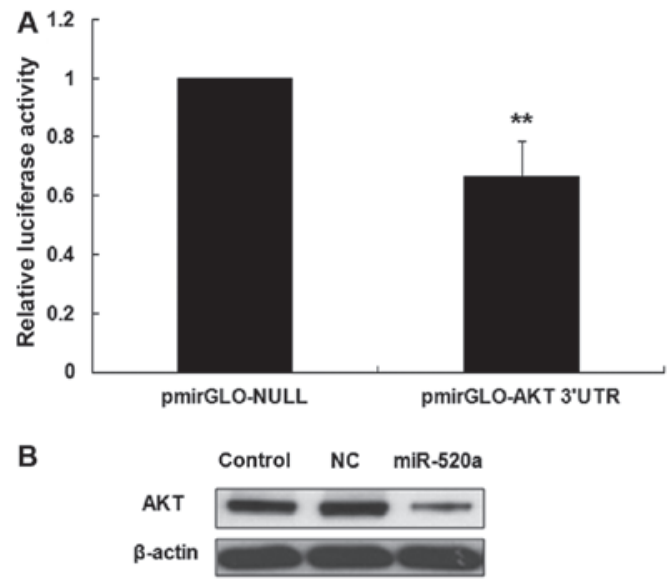

Figure 1. miR-520a inhibits the expression of AKT in HaCaT cells. (A) Relative luciferase activity of the 3'UTR of AKT in HaCaT cells. (B) Western blot analysis of the expression of AKT in the control, $\mathrm{NC}$ and $\mathrm{HaCaT}$ cells transfected with miR-520a. ${ }^{* *} \mathrm{P}<0.01$ vs. the control group. NC, negative control; miR, microRNA; UTR, untranslated region; AKT, protein kinase B.

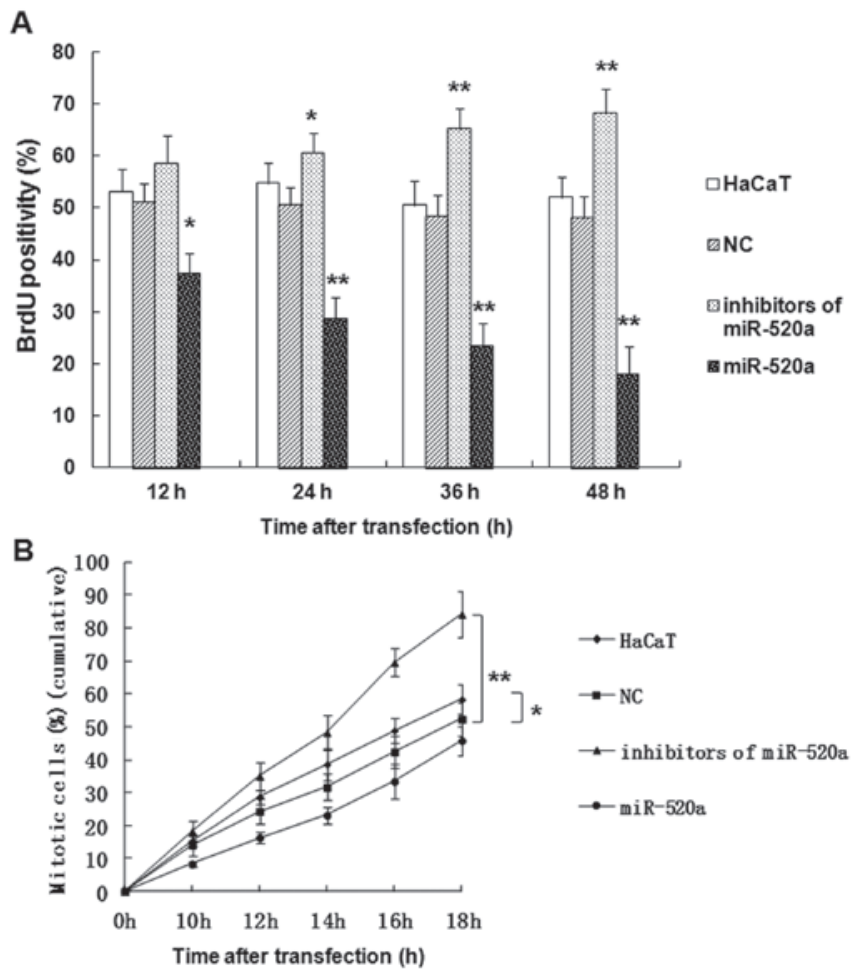

Figure 2. miR-520a inhibits the mitotic entry and proliferation of HaCaT cells. The percentage of (A) BrdU positive cells and (B) mitotic cells in the $\mathrm{NC}, \mathrm{HaCaT}$, miR-520a inhibitor and miR-520a mimic groups following transfection. ${ }^{*} \mathrm{P}<0.05,{ }^{* * *} \mathrm{P}<0.01$ vs. the $\mathrm{NC}$ group. NC, negative control; miR, microRNA; BrdU, bromodeoxyuridine.

obtained at $10 \mathrm{~min}$ intervals. Mitotic events in the cells were detected by changes in morphology. Mitotic cells were counted based on DNA condensation and nuclear morphology.

Detection of apoptosis. HaCaT cells fluorescently stained for $15 \mathrm{~min}$ at room temperature with Annexin V-FITC/propidium iodide (PI) from MitoCapture Apoptosis Detection kit (BioVision, San Francisco, CA, USA) were analyzed using a flow cytometer at 12, 24, 36 and 48 h following treatment

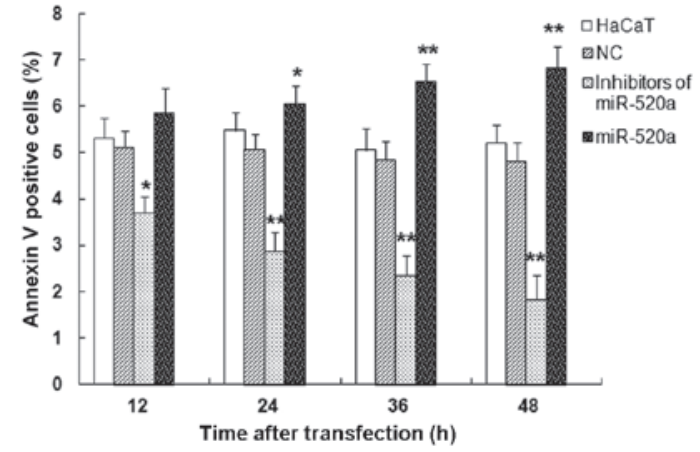

Figure 3. miR-520a promotes the apoptosis of HaCaT cells. Flow cytometry analysis of Annexin $\mathrm{V}$ and propidium iodide stained $\mathrm{HaCaT}$ cells. ${ }^{*} \mathrm{P}<0.05$, ${ }^{* *} \mathrm{P}<0.01$ vs. the NC group. NC, negative control; miR, microRNA.

with miR-520a mimics or inhibitors. Annexin V-FITC and PI were excited by the 488 or $532 \mathrm{~nm}$ laser emitted at wavelengths $>610 \mathrm{~nm}$. The flow cytometry (FCS) filter was used to filter the data files. The program has been designed to gate out microbead populations and remove debris and other unnecessary events from the FCS data files that may interfere with the clustering procedure of the FCAP Array software. The filtering process is based on a gate defined by the user. The gate should be defined on a single FCS data file and the FCS Filter program will automatically apply the same gate for all FCS files in a selected folder. The software saves the filtered events into new FCS 2.0 data files and keeps the original files. Data analysis was performed using FlowJo software version 7.6.3 (FlowJo LLC, Ashland, OR, USA).

Statistical analysis. Continuous variables were determined to be normally distributed using SPSS software (version 18.0; SPSS, Inc., Chicago, IL, USA). Data are expressed as the mean \pm standard deviation from three independent experiments. A unpaired Student's t-test or one-way analysis of variance and post hoc pairwise multiple comparisons tests were used for the comparisons of multiple groups. Data with a non-normal distribution were analyzed using the Kruskal-Wallis test. $\mathrm{P}<0.05$ was determined to indicate statistically significant difference.

\section{Results}

miR-520a inhibits the expression of AKT in HaCaT cells. DIANA microT software was used to identify the targets of miR-520a in HaCaT cells. The 3'UTR of AKT mRNA was identified as a potential target of miR-520a (data not shown). It was then demonstrated that the luciferase activity of the AKT 3'UTR was significantly reduced in miR-520a treated HaCaT cells compared with the control group $(\mathrm{P}<0.001$; Fig. 1A). Western blotting then revealed that miR-520a notably inhibited the expression of AKT in HaCaT cells (Fig. 1B).

miR-520a suppresses the mitotic entry and proliferation of $\mathrm{HaCaT}$ cells. The role served by miR-520a in HaCaT cells was further investigated using a BrdU assay (Fig. 2). The results indicated that miR-520a significantly suppressed the proliferation $(\mathrm{P}<0.05$; Fig. $2 \mathrm{~A})$ and mitotic entry $(\mathrm{P}<0.05$; Fig. $2 \mathrm{~B})$ of $\mathrm{HaCaT}$ cells in a time-dependent manner, while the inhibitors 
A

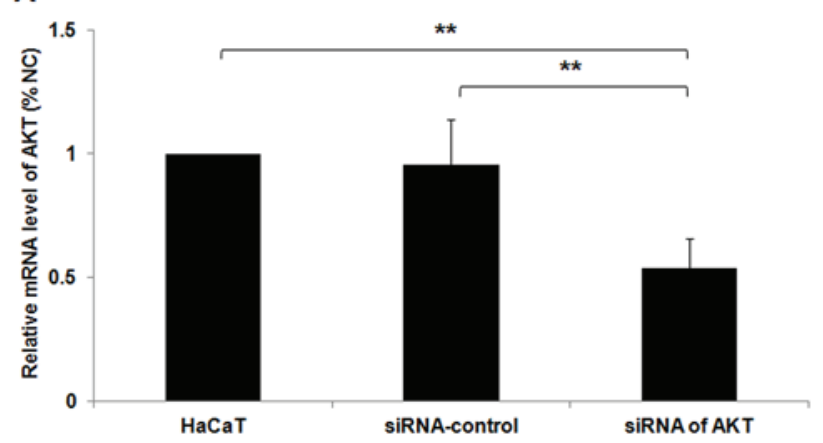

c

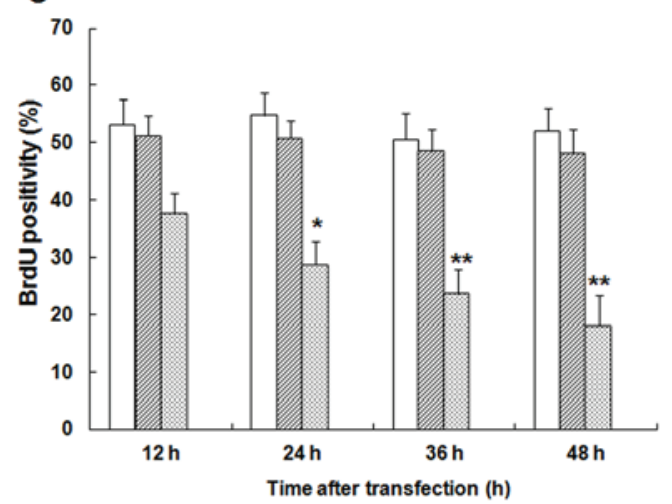

B
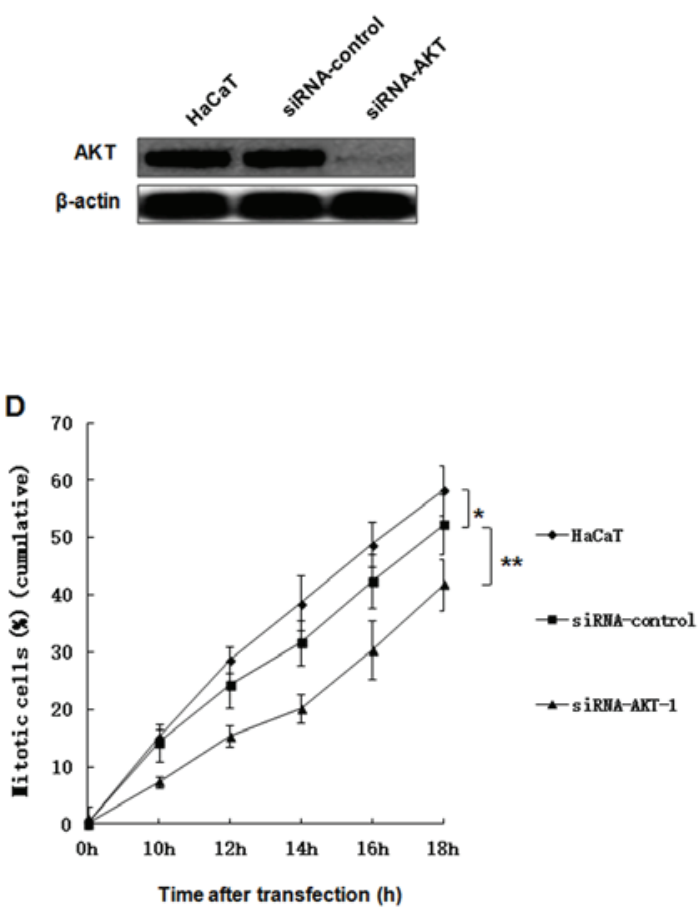

Figure 4. siRNA silencing of AKT represses the proliferation and mitosis of HaCaT cells. Following the transfection of HaCaT cells with AKT-specific siRNA, the expression of AKT mRNA and protein was analyzed using (A) reverse transcription-quantitative polymerase chain reaction and (B) western blotting analyses, respectively. (C) The proliferation of HaCaT cells was determined at 12, 24,36 and 48 h following transfection using a BrdU assay. (D) The percentage of mitotic HaCaT cells were determined at $10,12,14,16$ and $18 \mathrm{~h}$ following transfection. ${ }^{*} \mathrm{P}<0.05$, ${ }^{* *} \mathrm{P}<0.01 \mathrm{vs}$. the siRNA control group; miR, microRNA; AKT, protein kinase B; siRNA, small interfering RNA.

of miR-520a promoted the proliferation $(\mathrm{P}<0.05$; Fig. 2A) and mitotic entry $(\mathrm{P}<0.01$; Fig. $2 \mathrm{~B})$ of $\mathrm{HaCaT}$ cells compared with the control group.

miR-520a induces HaCaT cell apoptosis. Flow cytometry was used to measure the apoptosis induced by miR-520a mimics and inhibitors (Fig. 3). The mimics of miR-520a significantly increased $\mathrm{HaCaT}$ cell apoptosis in a time-dependent manner, while the inhibitors of miR-520a repressed HaCaT cell apoptosis (all $\mathrm{P}<0.05$ vs. the control group). These results indicate that miR-520a suppresses the survival of HaCaT cells.

The function of AKT in HaCaT cell proliferation and mitosis. AKT is a key regulatory factor of cell proliferation (21). In the present study, the expression of AKT was knocked down in a HaCaT cell model via siRNA silencing. The expression of AKT was examined using western blot analysis and RT-qPCR. The proliferation and mitosis of HaCaT cells were then detected. The results confirmed that specific siRNAs for AKT induced significant downregulation of AKT mRNA expression compared with the untransfected HaCaT cell group or the siRNA control group, respectively (Fig. 4A; $\mathrm{P}<0.01$ ). Furthermore, the protein expression of AKT was downregulated by siRNA (Fig. 4B). In addition, the decreased expression of AKT in HaCaT cells significantly suppressed the proliferation and mitosis of $\mathrm{HaCaT}$ cells in a time-dependent manner (Fig. 4C and D; all $\mathrm{P}<0.05$ vs. the siRNA control group).

\section{Discussion}

Psoriasis is a long-lasting autoimmune disease. Its primary clinical feature is skin injury, where the skin appears scaly, red and itchy. The severity of psoriasis varies from its presence in a small area to coverage of the entire body (22). The Koebner phenomenon is when Psoriatic changes occur depending on the location of skin lesions (23). Skin lesions may be pustular, guttate, erythrodermic, inverse or plaque (22). They are commonly located on the scalp, around the navel, shin and the back of the forearms $(24,25)$. Genetic factors associated with the immune reaction of skin cells serve a role in the pathogenesis of psoriasis, which may be affected by the environment, psychological stress or infections (22-24). However, the mechanisms of the pathogenesis of psoriasis remain unclear; therefore, further study is required. Furthermore, cardiovascular disease, lymphomas, psoriatic arthritis, depression and Crohn's disease may increase the risk of psoriasis (24).

There are no effective treatments for psoriasis; however, various therapies may be used to improve its symptoms (24), including ultraviolet light, vitamin $\mathrm{D}_{3}$ cream and immune system suppressing medications, such as methotrexate and steroid creams $(22,26)$. Genetic susceptibility serves a crucial role in the development of psoriasis $(27,28)$. The majority of genes associated with psoriasis have been identified as serving a role in the immune system, particularly in T cells and major histocompatibility complexes (29). Genomic research may potentially be used to identify the molecular mechanisms 
and pathways involved in psoriasis, as well as potential novel drug targets.

Classic genome-wide linkage analysis has indicated that there are nine loci on different chromosomes associated with psoriasis, including those containing genes whose products serve a role in inflammation, such as AKT (29-32). These loci are associated with the NF- $\mathrm{NB}$ and tumor necrosis factor (TNF)- $\alpha$ signaling pathways (29). In addition, T lymphocytes induce the abnormal proliferation of keratinocytes, which may trigger psoriasis (29).

During inflammation, TNF- $\alpha$ regulates its downstream molecules, including the transcription factors AKT or $\mathrm{NF}-\kappa \mathrm{B}$, and controls several cellular pathophysiological progressions (30). The crucial role served by AKT in cell proliferation and mitosis has been demonstrated previously (33). AKT is activated by a range stimuli and regulates multiple steps in angiogenesis, including invasion, migration and cell survival. The phosphorylation of AKT and the inhibition of the PI3K-AKT signaling pathway act upstream of $\mathrm{NF}-\kappa \mathrm{B}$, leading to its activation in acute inflammatory responses (34). However, the endogenous miRNA-dependent mechanisms of silencing AKT expression in HaCaT cells remain unknown. Thus, the present study investigated the upstream mechanisms of AKT activation associated with miRNA regulation.

The present study demonstrated that miR-520a inhibits the proliferation and mitotic entry of the human keratinocyte cell line $\mathrm{HaCaT}$. Furthermore, AKT was identified as a predicted target gene of miRNA-520a. A luciferase reporter assay was then used to confirm that miR-520a directly binds with the 3'UTR of AKT. The results indicated that in the 3'UTR of AKT, the relative luciferase activities were significantly decreased in HaCaT cells transfected with miR-520a. This confirmed that miR-520a directly regulates the expression of its target gene, AKT, at the mRNA and protein level.

miRNAs are non-coding RNAs that influence gene expression. They do this through mediating post-transcriptional gene silencing by suppressing the translation of mRNAs or degrading mRNAs. miRNAs serve a role in a variety of cellular processes, including differentiation, development, proliferation and tumorigenesis (35).

The present study aimed to investigate the role served by miR-520a in regulating the proliferation and mitosis of the human keratinocyte cell line $\mathrm{HaCaT}$. The results indicated that miR-520a directly regulates the expression of AKT, and significantly inhibits the mitotic entry and proliferation of $\mathrm{HaCaT}$ cells, while promoting apoptosis. Furthermore, the proliferation and mitotic entry of $\mathrm{HaCaT}$ cells was increased in a time-dependent manner by inhibiting miR-520a, and $\mathrm{HaCaT}$ apoptosis was inhibited. These results demonstrate that miR-520a suppresses HaCaT cell survival.

Knockdown of AKT was established in a HaCaT cell model via transfection with siRNAs specific for AKT. The results indicated that the expression of AKT was significantly downregulated, which significantly inhibited the mitotic entry and proliferation of $\mathrm{HaCaT}$ cells.

The present study only investigated one member of the PI3K-AKT-mammalian target of rapamycin kinase system; therefore, the regulation of the entirety of this cascade system by miRNA-520a remains unclear. Additionally, further investigation into the other effects of miRNA-520a in psoriasis, including its effect on NF- $\kappa \mathrm{B}, \mathrm{TNF}-\alpha$ and ER-stress is required. The challenges of using miRNA-520a as a treatment for patients with psoriasis may be solved by using mimics of miRNA-520a or siRNA specific for AKT.

In conclusion, the results of the present study indicate that miRNA-520a induces the downregulation of AKT expression, and suppresses the proliferation and mitotic entry of the human keratinocyte cell line $\mathrm{HaCaT}$ via the AKT signalling pathway. Thus, miRNA-520a and AKT may be a novel target for the treatment of psoriasis.

\section{Acknowledgements}

The present study was supported by the National Natural Science Foundation of China (grant no. 30600524; Beijing, China).

\section{References}

1. Nestle FO, Kaplan DH and Barker J: Psoriasis. N Engl J Med 361: 496-509, 2009

2. Gudjonsson JE and Elder JT: Psoriasis: Epidemiology. Clin Dermatol 25: 535-546, 2007.

3. Rahman M, Alam K, Ahmad MZ, Gupta G, Afzal M, Akhter S, Kazmi I, Jyoti, Ahmad FJ and Anwar F: Classical to current approach for treatment of psoriasis: A review. Endocr Metab Immune Disord Drug Targets 12: 287-302, 2012.

4. Menter A, Gottlieb A, Feldman SR, Van Voorhees AS, Leonardi CL, Gordon KB, Lebwohl M, Koo JY, Elmets CA, Korman NJ, et al: Guidelines of care for the management of psoriasis and psoriatic arthritis: Section 1. Overview of psoriasis and guidelines of care for the treatment of psoriasis with biologics. J Am Acad Dermatol 58: 826-850, 2008.

5. Garshick MK and Kimball AB: Psoriasis and the life cycle of persistent life effects. Dermatol Clin 33: 25-39, 2015.

6. Ambros V: The functions of animal microRNAs. Nature 431: 350-355, 2004.

7. Bartel DP: MicroRNAs: Genomics, biogenesis, mechanism, and function. Cell 116: 281-297, 2004.

8. Esteller M: Non-coding RNAs in human disease. Nat Rev Genet 12: 861-874, 2011.

9. Lewis BP, Shih IH, Jones-Rhoades MW, Bartel DP and Burge CB: Prediction of mammalian microRNA targets. Cell 115: 787-798, 2003.

10. He L and Hannon GJ: MicroRNAs: Small RNAs with a big role in gene regulation. Nat Rev Genet 5: 522-531, 2004.

11. Esquela-Kerscher A and Slack FJ: Oncomirs-microRNAs with a role in cancer. Nat Rev Cancer 6: 259-269, 2006.

12. Dong Y, Zou J, Su S, Huang H, Deng Y, Wang B and Li W: MicroRNA-218 and microRNA-520a inhibit cell proliferation by downregulating E2F2 in hepatocellular carcinoma. Mol Med Rep 12: 1016-1022, 2015.

13. Juan M, Shilong N, Xingxing W, Lu S, Fei J, Yuan L and Zhong L: The repressive effect of miR-520a on NF- $\mathrm{B}$ /IL-6/STAT-3 signal involved in the glabridin-induced anti-angiogenesis in human breast cancer cells. RSC Advances 5: 34257-34264, 2014.

14. Wang $X$, Wang $P$, Zhu $Y$, Zhang Z, Zhang J and Wang $H$ : MicroRNA-520a attenuates proliferation of Raji cells through inhibition of AKT1/NF- $\mathrm{B}$ and PERK/eIF2 $\alpha$ signaling pathway. Oncol Rep 36: 1702-1708, 2016.

15. Deyrieux AF and Wilson VG: In vitro culture conditions to study keratinocyte differentiation using the HaCaT cell line. Cytotechnology 54: 77-83, 2007.

16. Breitkreutz D, Schoop VM, Mirancea N, Baur M, Stark HJ and Fusenig NE: Epidermal differentiation and basement membrane formation by $\mathrm{HaCaT}$ cells in surfacetransplants. Eur J Cell Biol 75: 273-286, 1998.

17. Coppo R, Camilla R, Alfarano A, Balegno S, Mancuso D, Peruzzi L, Amore A, Dal Canton A, Sepe V and Tovo P: Upregulation of the immunoproteasome in peripheral blood mononuclear cells of patients with IgA nephropathy. Kidney Int 75: 536-541, 2009. 
18. Livak KJ and Schmittgen TD: Analysis of relative gene expression data using real-time quantitative PCR and the 2(-Delta Delta C(T). Method. Methods 25: 402-408, 2001.

19. Kumagai-Sano F, Hayashi T, Sano T and Hasezawa S: Cell cycle synchronizationn of tobacco BY-2 cells. Nat Protoc 1: 2621-2627, 2006.

20. Lei Y, Liu H, Yang Y, Wang X, Ren N, Li B, Liu S, Cheng J, Fu X and Zhang J: Interaction of LHBs with C53 promotes hepatocyte mitotic entry: A novel mechanism for HBV-induced hepatocellular carcinoma. Oncol Rep 27: 151-159, 2012.

21. Fu X, Wen H, Jing L, Yang Y, Wang W, Liang X, Nan K, Yao Y and Tian T: MicroRNA-155-5p promotes hepatocellular carcinoma progression by suppressing PTEN through the PI3K/Akt pathway. Cancer Sci 108: 620-631, 2017.

22. Meier M and Sheth PB: Clinical spectrum and severity of psoriasis. Curr Probl Dermatol 38: 1-20, 2009.

23. Khurrum H, AlGhamdi KM, Bedaiwi KM and AlBalahi NM: Multivariate analysis of factors associated with the koebner phenomenon in vitiligo: An observational study of 381 patients. Ann Dermatol 29: 302-306, 2017.

24. Boehncke WH and Schön MP: Psoriasis. Lancet 386: 983-994, 2015.

25. Sima J: Dermatology: Illustrated Study Guide and Comprehensive Board Review. Springer, New York, pp83-87, 2012. ISBN: 978-3-319-47395-6.

26. Parisi R, Symmons DP, Griffiths CE and Ashcroft DM; Identification and Management of Psoriasis and Associated ComorbidiTy (IMPACT) project team: Global epidemiology of psoriasis: A systematic review of incidence and prevalence. J Invest Dermatol 133: 377-385, 2013.
27. Tamparo CD and Lewis MA: Diseases of the Human Body. 5th edition. F.A. Davis Company, Philadelphia, PA, p180, 2011. ISBN-13: 978-0-8036-2505-1.

28. Krueger $\mathrm{G}$ and Ellis $\mathrm{CN}$ : Psoriasis-recent advances in understanding its pathogenesis and treatment. J Am Acad Dermatol 53 (Suppl 1): S94-S100, 2005.

29. Nestle FO, Kaplan DH and Barker J: Psoriasis. N Engl J Med 361: 496-509, 2009.

30. Yamamoto S, Yamane M, Yoshida O, Okazaki M, Waki N, Toyooka S, Oto T and Miyoshi S: Activations of mitogen-activated protein kinases and regulation of their downstream moleculesafter rat lung transplantation from donors after cardiac death. Transplant Proc 43: 3628-3633, 2011.

31. Smith $\mathrm{CH}$ and Barker JN: Psoriasis and its management. BMJ 333: 380-384, 2015.

32. Prieto-Pérez R, Cabaleiro T, Daudén E, Ochoa D, Roman M and Abad-Santos F: Genetics of Psoriasis and Pharmacogenetics of Biological Drugs. Autoimmune Dis 2013: 613086, 2013.

33. Beaudoin GM: Mosaic cellular patterning in the nose: Adhesion molecules give their two scents. J Cell Biol 212: 495-497, 2016.

34. Choi EK, Jang HC, Kim JH, Kim HJ, Kang HC, Paek YW, Lee HC, Lee SH, Oh WM and Kang IC: Enhancement of cytokine-mediated NF-kappaB activation by phosphatidylinositol 3-kinase inhibitors inmonocytic cells. Int Immunopharmacol 6: 908-915, 2006.

35. Filipowicz W, Bhattacharyya SN and Sonenberg N: Mechanisms of post-transcriptional regulation by microRNAs: Are the answers in sight? Nat Rev Genet 9: 102-114, 2008. 